\title{
Numerical study on the stratum's responses due to natural gas hydrate dissociation
}

\section{Lu, X. H. Zhang \& X. B. Lu}

To cite this article: L. Lu, X. H. Zhang \& X. B. Lu (2016): Numerical study on the stratum's responses due to natural gas hydrate dissociation, Ships and Offshore Structures, DOI: 10.1080/17445302.2016.1241366

To link to this article: http://dx.doi.org/10.1080/17445302.2016.1241366

\section{Published online: 11 Oct 2016.}

Submit your article to this journal ¿

Џ Article views: 5

Q View related articles $\square$

View Crossmark data $\longleftarrow$ 


\title{
Numerical study on the stratum's responses due to natural gas hydrate dissociation
}

\author{
L. Lu' ${ }^{a}$ X. H. Zhang ${ }^{b, c}$ and X. B. Lu ${ }^{b, c}$ \\ a Faculty of Physics, School of Science, China University of Mining and Technology, Beijing, China; ${ }^{b}$ Department of Engineering Sciences, University of \\ Chinese Academy of Sciences, Beijing, China; 'Department of LMFS, Institute of Mechanics, Chinese Academy of Sciences, Beijing, China
}

\begin{abstract}
Natural gas hydrate (NGH) dissociation can cause many kinds of potential hazards. Dimensional analysis is used first to obtain the controlling factors for NGH dissociation-induced stratum's responses. And then the effects of the controlling factors on the deformation and stress distribution have then been numerically investigated. A simplified critical condition for judging the instability of gentle inclined stratum after NGH dissociation was proposed. It is shown that the maximum settlement is located near the upper part of the slide body while the soil uplifts near the lower part. The fast change of the stress and deformation is located at the interface between hydrate-bearing stratum (HBS) and over layer. The slope angle has the largest effects on the responses of the stratum. The effects of modulus and water depth on the stratum's instability are small. There is a critical extension length of dissociation zone over which landslide will occur which is determined by the strength parameters, slope angle, friction coefficient and height of the over layer.
\end{abstract}

\section{ARTICLE HISTORY}

Received 27 June 2016

Accepted 22 September 2016

\section{KEYWORDS}

Gas hydrate; dissociation zone; slope instability; deformation

\section{Introduction}

Natural gas hydrate (NGH) is a kind of crystalline solid composed mainly of methane gas molecules and water molecules which is stabilised in conditions of high pressure and low temperature. It is distributed extensively in deep sea, lake and permafrost area. Extraction of methane from NGH can provide a future strategic energy resource in the twenty-first century (Sloan 1998).

NGH is stabilised in high pressure and low temperature and prone to destabilise when the pressure or temperature changes (Briaud and Chaouch 1997). The destabilisation can directly change the strength of hydrate-bearing stratum (HBS). Generally, $1 \mathrm{~m}^{3} \mathrm{NGH}$ can release $164 \mathrm{~m}^{3}$ methane gas and $0.8 \mathrm{~m}^{3}$ water at $1 \mathrm{~atm}$ and normal temperature. The released gas and water, if do not drain quickly, will greatly increase the excess pore gas pressure and reduce the HBS strength, and accordingly cause environmental and geological disasters (Song 2003; $\mathrm{Hu}$ et al. 2004) and engineering damages, such as destruction of seabed, wellbore, foundation, etc. (Milkov 2000; Xu and Germanovich 2006; Zhang et al. 2010, 2011). A typical event of such disaster is the famous Storegga landslide, which is believed to be caused by thermal dissociation of NGH (Bugge et al. 1987). It occurred under water at the edge of the Norwegian continental shelf and is the largest known landslides, resulting in $2500-3200 \mathrm{~km}^{3}$ sediment. This event caused heavy tsunamis and widespread flooding and devastation along the continental littoral. Another example is the US mid-Atlantic coast slide, mainly caused by NGH dissociation due to the rise of the sea water temperature (Jung and Peter 2004).

Many ocean oil and gas explorations are operated at HBS area, and thus impose on NGH dissociation (Chaouch and Briaud 1997; Zhang et al. 2010). For example, many researchers thought that formation and dissociation of $\mathrm{NGH}$ is the main reason of the Deepwater Horizon explosion in the Gulf Mexico (Qing et al. 2011; Marcia et al. 2012) though the cause of this accident is still in debate because some thought the NGH dissociation is too slow to induce blowout ( $\mathrm{Li}$ et al. 2015, 2016). The failure of the giant steel dome to stop the drainage of oil in this accident was observed to be caused by the formation of NGH (Qing et al. 2011).

NGH dissociation front around a high temperature oil pipe in HBS can expand gradually and cause the stratum instability and wellbore instability (Briaud and Chaouch 1997). If NGH in HBS dissociates without seepage, an excess pore pressure of more than $40 \mathrm{MPa}$ can form at initial NGH fraction of 0.2 and temperature of $6{ }^{\circ} \mathrm{C}$. The excess pore pressure increases with the rise of NGH fraction and stratum stiffness (Xu and Germanovich 2006; Kwon et al. 2008).

Several studies on gas extraction from HBS have been carried out (Wang et al. 2009; Lu et al. 2010; Li et al. 2015, 2016). However, little is known about the deformation and stability of stratum due to NGH dissociation. Liu et al. (2010) investigated the slope instability in the South China Sea, showing that dissociation of only $5 \%$ of NGH in stratum is enough to cause instability for slope of $20^{\circ}$, and $15 \%$ of NGH for slope of $5^{\circ}$. Zhang et al. (2014) investigated the time sequence of NGH formation and landslide and its relation to the NGH exploitation. Their work shows that the pre-gas hydrate landslides are most favourable for the preservation and exploitation of the gas hydrate, while the syn-gas hydrate landslides are the secondary favourable sites. An et al. (2011) reported that the burial depth and internal friction angle and excess pore pressure greatly affected the formation of a gentle landslide due to NGH dissociation based on the upper limit method of energy. The detailed responses of 
deformation and stress fields, controlling factors and the instability mechanism are still lacking.

In this paper, numerical simulation is used to investigate the responses of HBS with NGH dissociation. Deformation and stress development, initiation conditions of sliding are mainly investigated. A simple critical condition for judging the instability of a gentle slope after NGH dissociation is presented.

\subsection{Dimensional analysis}

The problem considered in this paper is the NGH dissociation related instability of a submarine slope with three layers: over layer, HBS and lower layer from top to bottom. Obviously, this problem involves many factors. In order to find the controlling parameters for simplifying the problem, dimensional analysis is conducted. The effects of the lower layer to slope's responses can be neglected considering that its strength and stiffness are greatly larger than that of HBS. The factors can be divided into four types: (1) parameters of the over layer: thickness of soil layer $h$, slope angle $\theta$, density $\rho_{s}$, permeability $k$, elastic modulus $E$, Poisson's ratio $\nu$, cohesion $C$, internal friction angle $\varphi$; (2) parameters of the interface: friction coefficient, $f$; (3) parameters of HBS before/after NGH dissociation: length of dissociation zone $L$, thickness $H$, slope angle $\theta$, density $\rho_{\text {si }}$, permeability $k_{i}$, elastic modulus $E_{i}$, Poisson's ratio $v_{i}$, cohesion $C_{i}$, internal friction angle $\varphi_{i}(i=1,2$ indicates before and after NGH dissociation, respectively); (4) others: Earth gravity $g$, water depth $h_{w}$. The responses of stratum such as displacement $U$ and critical index of slope instability can be written as a function of the factors

$$
\begin{aligned}
\left\{U, C_{r}\right\}= & f\left(h, \theta, \rho_{s}, E, \nu, C, \varphi, H, \rho_{s i}, E_{i},\right. \\
& \left.v_{i}, C_{i}, \varphi_{i}, f, g, L, h_{w}\right)
\end{aligned}
$$

The dimensionless form can be expressed as

$$
\begin{aligned}
\left\{\frac{U}{h}, C_{r}\right\}= & f\left(\theta, \frac{\rho_{s} g h}{E}, v, \frac{C}{\rho_{s} g h \sqrt{h / g}},\right. \\
& \left.\varphi, \frac{H}{h}, \frac{E_{i}}{E} v_{i}, \frac{C_{i}}{c}, \varphi_{i}, f, \frac{L}{h}, \frac{, h_{w}}{h}\right)
\end{aligned}
$$

In practice, the Poisson's ratio changes little. So the responses of a stratum to NGH dissociation are mainly affected by the following dimensionless factors: slope angle, $\theta$ which is related to the driving force; ratio of gravity potential energy to elastic modulus $\left(\rho_{s} g h / E\right)$ which determines the potential of deformation; strength parameters (dimensionless cohesion $C /\left(\rho_{s} g h h^{0.5} g^{-0.5}\right)$ and dimensionless internal friction angle, $\varphi$ ) which determine the yield of stratum; scale ratio $H / h$; relative stiffness of HBS to over layer $\left(E_{i} / E\right)$ which determines the relative deformation, relative cohesion of HBS to over layer $\left(c_{i} / c\right)$, internal friction angle of HBS $\left(\varphi_{i}\right)$, friction at the interface which determine the resistance of the slope to slide $(f)$; relative length of dissociation zone which indicates affection range of dissociation zone $(L / h)$, relative water depth $\left(h_{w} / h\right)$ which determines the effects of water depth.

Since the responses of stratum investigated is induced by the NGH dissociation, only the dimensionless parameters related with that in dissociation zone are required to be considered. Thus, the dimensionless controlling parameters in Equation (3) will be used in numerical simulation and discussion in the following sections.

$$
\left\{\frac{U}{h}, C_{r}\right\}=f\left(\theta, \frac{E_{2}}{E}, \frac{C_{2}}{c}, \varphi_{2}, \frac{L}{h}, \frac{h_{w}}{h}\right)
$$

\section{Numerical model}

Software FLAC3D (Fast Lagrangian Analysis of Continua) is used for numerical simulation. FLAC3D is developed by the Itasac Consulting Group Inc. and University of Minnesota in USA (Itasca Consulting Group 2002) which can conveniently simulate the plastic failure and large scale deformation and distortion by using the mixed discretisation technique and the Lagrange algorithm.

In numerical model, the stratum is consisted of three layers: the upper soft soil (over layer), $200 \mathrm{~m}$; the middle HBS, $20 \mathrm{~m}$; the lower rock layer, $200 \mathrm{~m}$ and much stiffer than HBS. The stratum is with perfect seepage channel so that no pore pressure is accumulated during NGH dissociation. The material parameters of the stratum, shown in Table 1, were obtained by triaxial tests and physical property tests (Zheng et al. 2004; Lu et al. 2008).

Inside the area $100 \mathrm{~m}$ away from the wellbore, the scale of the network is length $\times$ height $=8.7 \mathrm{~m} \times 10 \mathrm{~m}$, and outside this area, it is $70 \mathrm{~m} \times 10 \mathrm{~m}$. In this way to reduce the total number of elements and keep enough accuracy. The sketch for numerical simulation is shown in Figure 1.

HBS can be thought as a kind of special soil in which NGH is on one hand as a part of the skeleton that can bear load and on the other hand is a kind of binder to cement the stratum's grains. Thus, the Mohr-Column constitutive relation applies to HBS (Zhang et al. 2012). The surface of the stratum was free. In the direction along the slope, the length adopted in the simulation is long enough $(200-10,000 \mathrm{~m})$ to avoid the boundary effects, with the normal displacements being zero at the ends. The lower layer is adopted thick enough to satisfy the displacement at the bottom maintaining zero (Figure 1). At the interface between the over layer and HBS, the displacement is continuous and the friction is assumed to decrease to zero once NGH here is dissociated. Because the propagation of stress in the

Table 1. The material parameters of the stratum.

\begin{tabular}{lcccc}
\hline & Modulus (MPa) & Cohesion $(\mathrm{kN})$ & Internal friction angle $\left(^{\circ}\right)$ & Density $\left(\mathrm{kg} / \mathrm{m}^{3}\right)$ \\
\hline Over layer & 1.0 & 10.0 & 20 & 2000 \\
HBS before NGH dissociation & 186.0 & 0.0 & 39.4 & 2150 \\
HBS after NGH dissociation & 18.6 & 0.0 & 3 & 2110 \\
Lower layer & 500.0 & 30.0 & 32 & 2400 \\
\hline
\end{tabular}




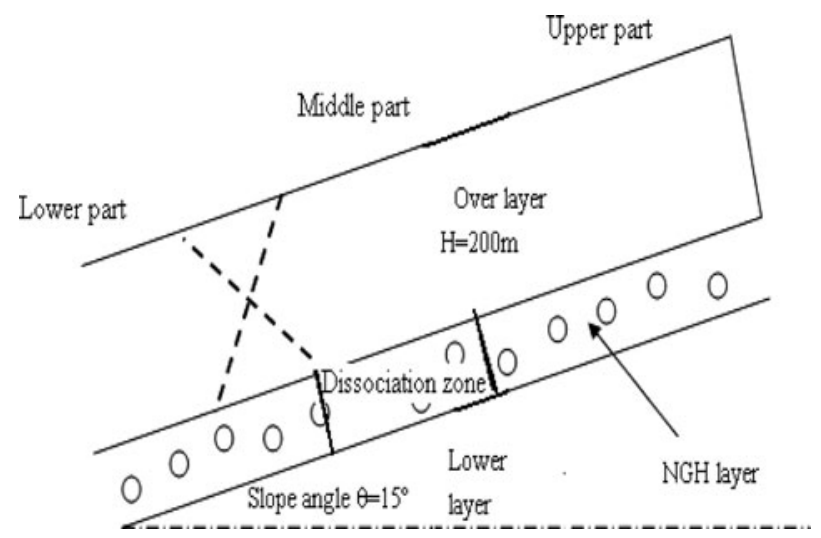

Figure 1. Sketch of numerical model.

stratum is faster than the conduction of seepage and NGH dissociation (Zhang et al. 2010), seepage and dissociation processes were assumed to happen earlier than the changes of stress in the numerical simulation. That means, the stress and displacement change immediately after the seepage and NGH dissociation. NGH dissociation was caused by the heat released from a vertical pipe or wellbore so the dissociation zone started from the vertical centre line of the stratum and expanded away.

\subsection{Numerical results and analysis}

\subsubsection{Displacements in the over layer at a given dissociation} zone length

Figure 2 shows the horizontal displacement (parallel to the slope surface) at different vertical sections when the dissociation zone length is $480 \mathrm{~m}$. Because the computation indicates that once the dissociation length is over $490 \mathrm{~m}$, the slope begins sliding, so here the data at dissociation length $480 \mathrm{~m}$ is adopted for analysis. The range of the $x$-coordination is from the left side (lower part) to the right side of the dissociation zone. It is smaller at the lower part than that at the upper part of the slope because of the restriction of the non-dissociated zone. At the lower part the stratum uplifts. The maximal displacement in the middle part

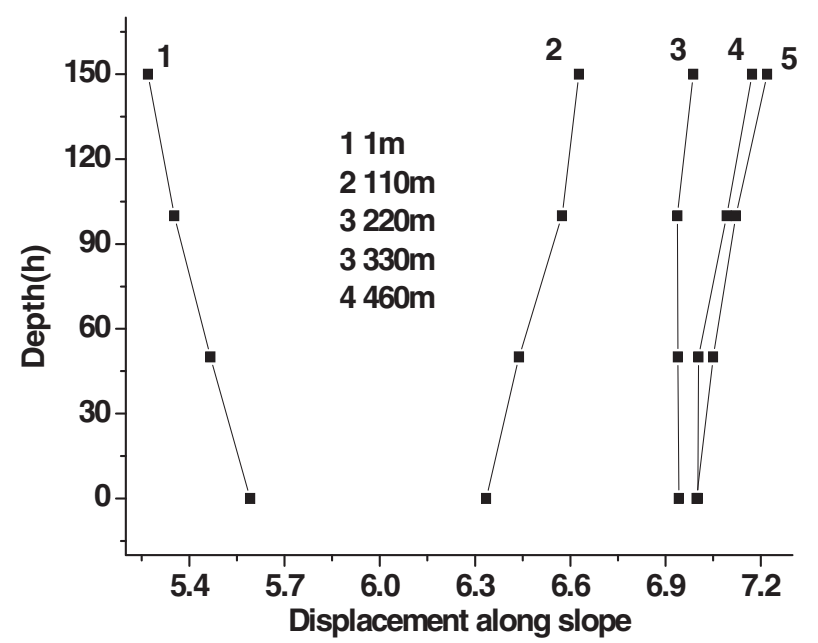

Figure 2. Horizontal displacement along horizontal direction with $480 \mathrm{~m}$ dissociation length ( $1-5$ denote the distance from the left end).

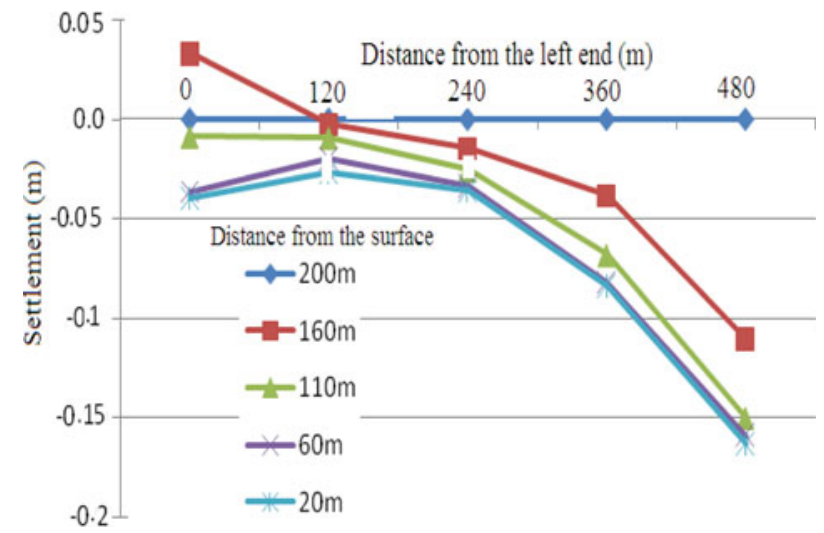

Figure 3. Changes of displacement vertical to slope surface at different depth. (This figure is available in colour online.)

occurs at the interface, at the upper part it is close to the bottom and at the lower part it is near the surface.

Figure 3 shows the vertical displacement (vertical to the slope surface) decreasing with depth. At the upper part the soil layer settles obviously, while at the lower part it settles little and even uplifts. The horizontal and vertical displacements indicate that the zone, a little larger than the dissociation zone in the over layer, has obvious displacements. The reason is that the strength and stiffness loss of the dissociation zone causes its support to the over layer decrease greatly. The over layer above the right boundary of the dissociation zone bears pulling stress due to the settlement, while above the left boundary bears the pressing stress. The scale of the affected zone is determined by the loss degree of the strength and stiffness and the strength of the over layer. The loss of strength and stiffness reduces the support of NGH layer to the over layer and thus results in a large affected zone.

The points of the largest horizontal displacements at vertical sections form a sliding surface, which can be seen by the velocity vector of the stratum (Figure 4). At the lower part, the stratum moves obliquely upwards and it moves obliquely downwards at the upper part. At the middle part, it almost moves along the slope. The interface between the dissociated HBS and the over layer form the main sliding surface.

\subsubsection{Displacement with the length of dissociation zone}

From Figure 5, it can be seen that the horizontal displacement increases slowly when the length of dissociation zone is less

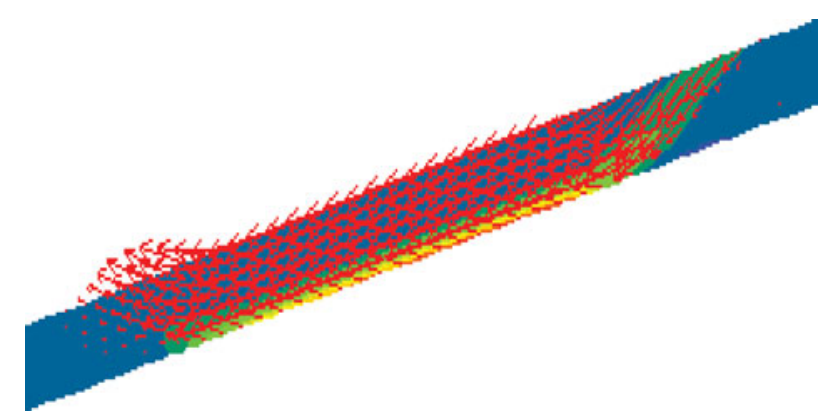

Figure 4. Velocity vector at the dissociation zone in length of $480 \mathrm{~m}$. (This figure is available in colour online.) 


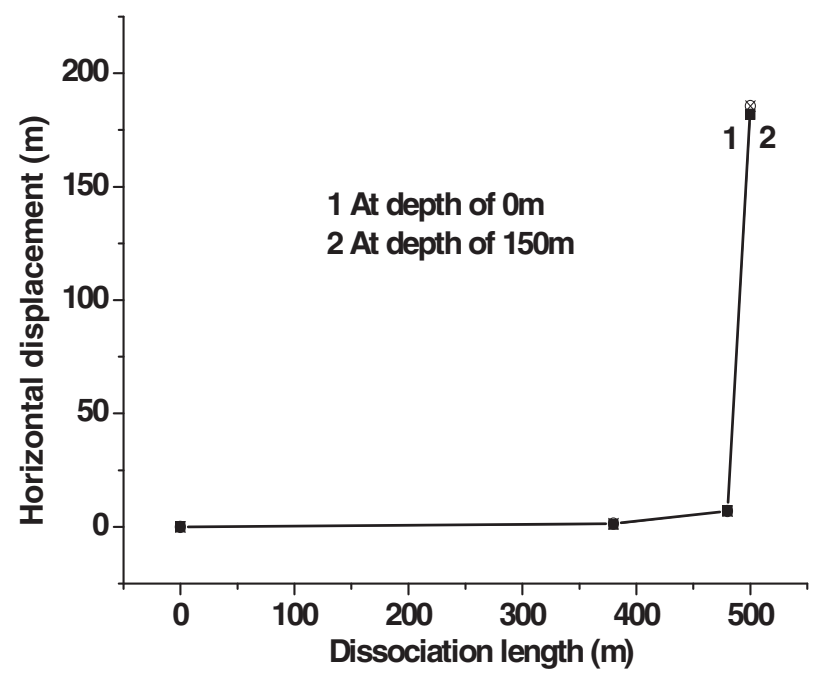

Figure 5. Horizontal displacement under different dissociation length.

than $480 \mathrm{~m}$ in the condition adopted in the computation. The horizontal displacement increases very fast once the dissociation length is over $480 \mathrm{~m}$. It indicates that once the dissociation length is larger than a value for a given condition, the stratum becomes instable and begins to slide. Thus, the responses of the stratum due to NGH dissociation can be thought as catastrophic. The critical length will be analysed in Section 2.1.5. The critical relative length $(L / h)$ is 2.4 in this case, which means a critical point for the instability of stratum.

\subsubsection{Shear stress with the length of dissociation zone}

Figure 6 shows that the shear stress in the middle part of the slope is larger than that at the lower and upper parts along the slope. The shear stress reaches the top at the interface between HBS and the over layer and makes it the potential slide surface, where the strength and stiffness of the stratum are discontinuous, and stress concentrates. The NGH dissociation greatly induces the stratum strength and moves HBS similar to the plate flow.

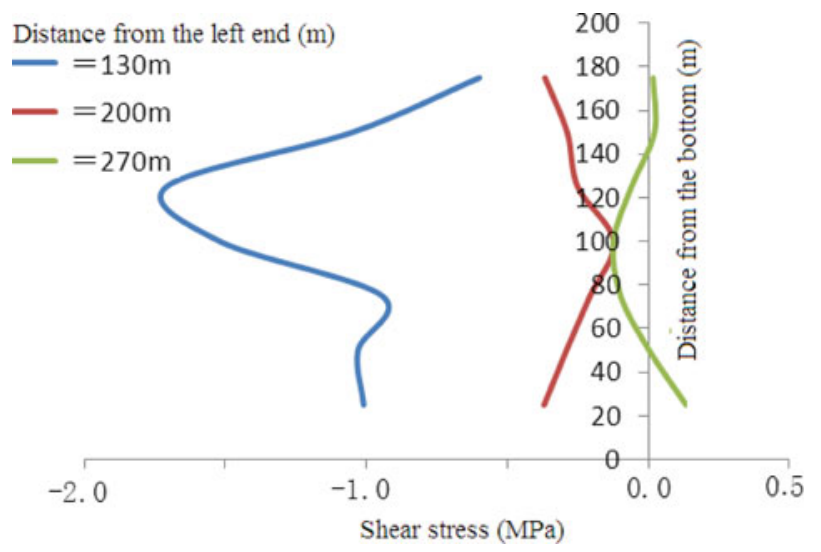

Figure 6. Distribution of shear stress along depth (height ratio $=1$ ). (This figure is available in colour online.)

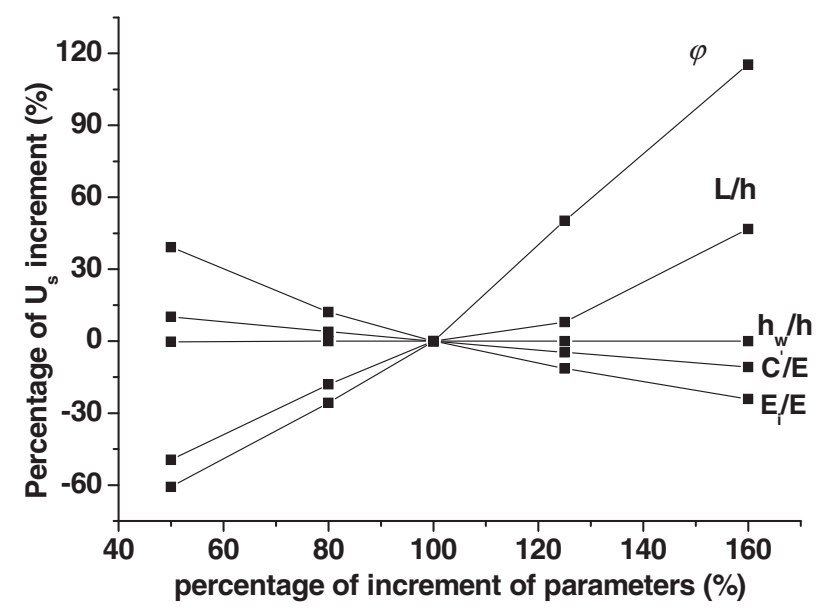

Figure 7. Effects of main factors on the deformation of sediment.

2.1.4. Effects of main factors on the responses of the stratum The dimensional analysis indicates that the main factors influencing the response are $\theta, E_{2} / E, c_{2} / c, \varphi_{2}, L / h$ and $h_{w} / h$, where $E_{2}, c_{2}$ and $\varphi_{2}$ are modulus, cohesion and internal friction angle after NGH dissociation, respectively. Now we investigate how the displacement along slope changes with respect to the variation of the factors. At first, we take the following basic values: $L=100 \mathrm{~m}, \theta=10^{\circ}, h=200 \mathrm{~m}, E=3.83 E+07, C=1000 \mathrm{~Pa}$, $E_{2}=5.84 E+07, C_{2}=0.1 \mathrm{MPa}, \varphi_{2}=5^{\circ}$.

The results shown in Figure 7 indicate that the deformation increases with slope angle and the relative length of dissociation zone, but decreases with the dimensionless modulus, dimensionless cohesion and relative water depth. The effects of the slope angle are the largest in all the parameters. The second is the relative length of the dissociation zone. For example, when the increment percentage is from $100 \%$ to $160 \%, 116 \%$ increment in displacement can be induced by the increment of slope angle and $46.8 \%$ by the increment of the relative length of dissociation zone. The relative water depth has little effects on the responses. The effects of the dimensionless modulus are less than $30 \%$. NGH dissociation reduces the interface resistance to the over lay, and the component of the gravity along the slope (driving force for slide) increases with slope angle, so the dissociation length and slope angle are the two key factors for the response of stratum. The increase in water depth changes little of the effective stress and strength when the seepage channel in the over layer is perfect because the water weight's components along the slope (drive force) and vertical to the slope (resistance) increase proportionally, and the internal friction angles and cohesion are small after NGH dissociation, thus these three factors' effects are small. The increase in modulus leads to more limitations on the stratum and decreases the displacement but no limitation on the strength.

\subsubsection{Analysis of critical dissociation length}

Practically, considering the strength failure of the slope, cohesion and internal friction form the resistance. The interaction between this resistance and the driving force provided by gravity component along slope determines the stability state of 
the slope. Dimensional analysis shows that the stratum instability due to NGH dissociation is mainly related with the dissociation length, the mechanical parameters of the over layer, slope angle and interface resistance. Thus, the criterion for the failure of a gentle HBS slope can be written as follows by choosing and recombining the parameters in Equation (3) remembering that the slide is due to the competition of the driving force and resistance:

$$
C_{r}=f\left(\frac{G L \sin \theta}{[G \cos \theta \tan \varphi+C] F(h)+f L}\right)
$$

in which the numerator in the right indicates the driving force and the denominator indicates the resistance for slide, $G=$ $\rho_{s} g h+\rho_{w} g h$ if the over layer is impermeable, that means, the pressure induced by the sea water cannot well connect with the pore fluid. Otherwise, $G=\left(\rho_{s}-\rho_{w}\right) g h_{w}$. $F(h)$ indicates the length of the slide face in the over layer and can be expressed as follows according to the limit equilibrium theory.

$$
F(h)=\frac{h}{\cos \left(45^{\circ}+0.5 \varphi\right)}
$$

Equation (4) means that the responses of a slope are determined mainly by the ratio of the resistance to the driving force. It can be rewritten as

$$
C_{r}=\frac{G L \sin \theta}{[G \cos \theta \tan \varphi+C] F(h)+f L} \geq 1.0
$$

So the critical dissociation length can be found as

$$
L \geq \frac{(G \cos \theta \tan \varphi+C) F(h)}{\rho_{s} g h \sin \theta-f}
$$

If the over layer is sandy soils, e.g. $C=0$ and the friction at the interface is zero, then the above equation becomes

$$
\frac{L}{h} \geq \frac{\cos \theta \tan \varphi}{\sin \theta \cos \left(45^{\circ}+0.5 \varphi\right)}
$$

This equation indicates that the instability condition in this case is not related with the gravity. Instituting the data used in numerical simulation (in Section 2) into the above equation, we can get $L / h=2.4$. It is close to the numerical results (the data in Section 2.1.2).

\subsubsection{Verification of the numerical simulation}

Numerical results are compared with the experimental results. The experiments were carried out in a model box with length $x$ width $\times$ height $=1.4 \mathrm{~m} \times 0.5 \mathrm{~m} \times 0.5 \mathrm{~m}$. The slope top of HBS was with height of $0.3 \mathrm{~m}$, and the slope angle is $15^{\circ}$. The density is $1600 \mathrm{~kg} / \mathrm{m}^{3}$. The specific gravity is 2.69 . When HBS sample was prepared, the box was opened to the air to let the temperature in the sample to rise. NGH in the stratum dissociated and the slope deformed gradually with the decrease of the strength and stiffness. The settlement at the slope surface was measured with linear variable differential transducers (LVDT). Meanwhile, the time and dissociation range were recorded as

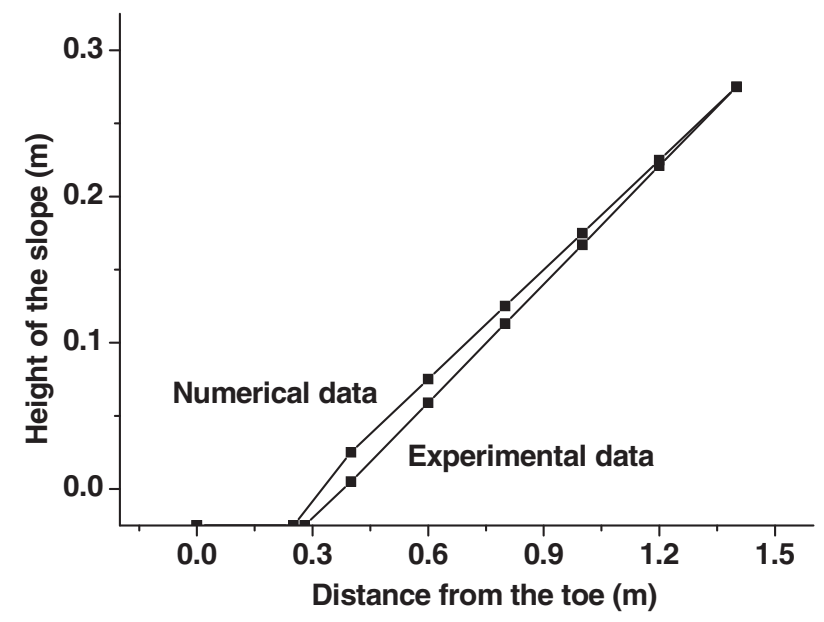

Figure 8. Comparison of numerical results and experimental results.

well. The material parameters were determined by triaxial tests with the stratum used in the model experiments. Cohesion and internal friction angle were obtained as $4.6 \mathrm{KPa}$ and $2.3^{\circ}$. In computation, the Mohr-Column constitutive relation was adopted. Figure 8 shows the comparison between numerical results and experimental results. In experiments, the settlement of the slope is obvious and easy to measure accurately, so it is used for comparison with the numerical results. Both results have the same tendency that the settlement is small at the toe and increases gradually towards the top of the slope because of the large height of the slope at the top. It can also be seen that these two agree well with each other.

\section{Conclusions}

Deformation, stress and instability of HBS during/after dissociation of gas hydrate have been numerically investigated. Main conclusions of this paper are as follows:

(1) The maximum settlement is located near the slope top. The soil near the toe uplifts.

(2) The response of the stratum due to NGH dissociation is catastrophic. There is a critical extension length of dissociation zone over which landslide will occur. The critical value is determined by the strength parameters, slope angle, friction coefficient and height of the over layer.

(3) Initiation condition of landslide due to NGH dissociation can be expressed as a simple formula at small slope angle which is the competition of the gravity along slope and the sum of the frictional force at the interface and the maximum shear force in the over layer.

(4) The effects of the slope angle are the largest in all the parameters. The second is the relative length of the dissociation zone. The relative water depth and dimensionless modulus have little effects on the responses.

(5) The thickness ratio of the NGH layer to the over layer is beneficial to the stability of stratum. Its rise leads to the increase of the critical length and their relation is in exponential form. 


\section{Funding}

This paper is supported by The National Natural Science Foundation of China [grant number 11272314], [grant number 51239010], [grant number 11102209]; Project of CAS-CNPC Strategic Alliance.

\section{References}

An CG, Zhang JH, Zhou M, Zhu Z. 2011. Analysis on the sliding mechanism of submarine gentle slope based on the upper limit of energy method. Northwest Seismol J Eng. B08:105-209. Chinese.

Briaud JL, Chaouch AJ. 1997. Hydrate melting in hydrate soil around hot conductor. J Geotech Geoenviron Eng. 123(7):645-653.

Bugge T, Befring S, Belderson RH, Eidvin T, Jansen E, Kenyon NH, Holtedahl H, Sejrup HP. 1987. A giant three-stage submarine slide off Norway. Geo-Mar Lett. 17(4):191-198.

Chaouch A, Briaud JL. 1997. Post melting behavior of gas hydrates in soft ocean sediments. Offshore Tech Conf. 1-11.

Hu GH, Liu ZC, Sun YF, Zhang XL. 2004. Advances in the research on sediment failure on submarine slope. Coast Eng. 23(1):63-72.

Itasca Consulting Group Inc. 2002. User's manual [Z]. (MN): Itasca Consulting Group.

Jung WY, Peter RV. 2004. Effects of bottom water warming and sea level rise on Holocene hydrate dissociation and mass wasting along the Norwegian-Barents Continental Margin. J Geophys Res. 109(B6):B06104.

Kwon TH, Cho GC, Santamarina GC. 2008. Gas hydrate dissociation in sediments: pressure-temperature evolution. Geochem Geophys Geosys. 9(3):Q03019.

Li M, Fan S, Su Y, Ezekiel J, Zhang L. 2015. Mathematical models of the heat-water dissociation of natural gas hydrates considering a moving Stefan boundary. Energy. 90:202-207.

Li M, Fan S, Su Y, Lu M. 2016. Numerical modeling of the physical parameters of the heated-water dissociation interface into the natural gas hydrates reservoir. Appl Therm Eng. 106:49-55.

Liu F, Wu SG, Sun YB. 2010. A quantitative analysis for submarine slope instability of the northern South China Sea due to gas hydrate dissociation. Chin J Geophys. 53(4):946-953. Chinese.

Lu XB, Li QP, Wang L, Wang SY. 2010. Instability of seabed and pipes induced by NGH dissociation. In: Proceedings of the 20th
International Offshore and Polar Engineering Conference; J Chuang ed., Beijing, China. ISOPE, p. 110-114.

Lu XB, Wang L, Wang SY, Li QP. 2008. Study on the mechanical properties of THF hydrate deposit. In: Proceedings of the 18th International Offshore and Polar Engineering Conference; J Chuang ed., Vancouver, Canada June 6-11: ISOPE. Vol 1, p. 57-60.

Marcia KM, Rich C, Timothy JC, George DG, Paul AH, Thomas BR, Omer S, Frank S. 2012. Review of flow rate estimates of the Deepwater Horizon oil spill. Proc Natl Acad Sci. 109(50):20260-20267.

Milkov AV. 2000. Worldwide distribution of submarine mud volcanoes and associated gas hydrates. Mar Geol. 167:29-42.

Qing ZL, Wu SG, Wang ZJ, Li QP. 2011. Geohazards and risk of deepwater engineering induced by gas hydrate - a case study from oil leakage of deepwater drilling well in GOM. Prog Geophys. 26(4): 1279-1284.

Sloan ED. 1998. Clathrates of natural gases. New York (NY): Dekker. p. 705. Song HB. 2003. Researches on dynamic evolution of gas hydrate system (II): submarine slides. Prog Geophys. 18(3):503-511. Chinese.

Wang SY, Zheng W, Lu XB. 2009. The effects of gas hydrate dissociation on the stability of pipeline in seabed. In: Proceedings of the 19th International Offshore and Polar Engineering Conference; J Chuang ed., Osaka, Japan, June 20-25: ISOPE. Vol 1, p. 49-53.

$\mathrm{Xu}$ W, Germanovich LN. 2006. Excess pore pressure resulting from methane hydrate dissociation in marine sediments: a theoretical approach. J Geophys Res. 111:B011104.

Zhang BK, Li SZ, Xia Z, Ma Y, Suo YH, Zhang GX, Wang XF, Yu S. 2014. Time sequence of submarine landslides and gas hydrates in the Northern South China Sea. Geotectonica Et Metallogenia. 38(2):434-440. Chinese.

Zhang XH, Lu XB, Li QP. 2010. Thermally induced evolution of phase transformations in gas hydrate sediment. Sci China Phys Mech Astron. 53(8):1530-1535.

Zhang XH, Lu XB, Zhang LM, Wang SY, Li QP. 2012. Experimental study on mechanical properties of methane-hydrate-bearing sediments. Acta Mech Sin. 28(5):1356-1366.

Zhang XH, Lu XB, Zheng ZM. 2011. Layered fracture and outburst due to dissociation of hydrate. J Petrol Sci Eng. 76:212-216.

Zheng ZC, Chen JR, Zhu ZY. 2004. Physical and mechanical characteristics of seabed soils and its geological environment in South China Sea. Hydrogeol \& Eng Geol. 31(4):50-53. 